\title{
Synthesis, Characterization and Antiparasitic Activity of Organometallic Derivatives of the Anthelmintic Drug Albendazole
}

\begin{abstract}
Yan Lin, ${ }^{a}$ Yih Ching Ong, ${ }^{a}$ Sarah Keller, ${ }^{a}$ Johannes Karges, ${ }^{a}$ Rafika Bouchene, ${ }^{b, c}$ Eric Manoury, ${ }^{b}$ Olivier Blacque, ${ }^{d}$ Joachim Müller, ${ }^{e}$ Nicoleta Anghel, ${ }^{e}$ Andrew Hemphill, ${ }^{e}$ Cécile Häberlig,h , Aya C. Taki, ${ }^{\text {Robin }}$ B. Gasser, ${ }^{f}$ Kevin Cariou, ${ }^{\mathrm{a}, *}$ Jennifer Keiser, ${ }^{\mathrm{g}, \mathrm{h}, *}{ }^{*}$ Gilles Gasser $^{\mathrm{a}, *}$
\end{abstract}

a) Chimie ParisTech, PSL University, CNRS, Institute of Chemistry for Life and Health Sciences, Laboratory for Inorganic Chemical Biology, 75005 Paris, France.

b) CNRS, LCC (Laboratoire de Chimie de Coordination), Université de Toulouse, UPS, INPT, 205 Route de Narbonne, BP 44099, 31077 Toulouse, France.

c) Département Sciences de la Matière, Faculté des Sciences Exactes, Université Larbi Ben M'hidi, BP 358, Route de Constantine, 04000 Oum El Bouaghi, Algeria.

d) Department of Chemistry, University of Zurich, Winterthurerstrasse 190, 8057 Zurich, Switzerland.

e) Institute of Parasitology, University of Bern, Länggass-Strasse 122, 3012 Bern, Switzerland.

f) Department of Veterinary Biosciences, Melbourne Veterinary School, Faculty of Veterinary and Agricultural Sciences, The University of Melbourne, Parkville, Victoria 3010, Australia.

g) Department of Medical Parasitology and Infection Biology, Swiss Tropical and Public Health Institute, Socinstr. 57, Basel, Switzerland.

h) University of Basel, Basel Switzerland. 


\section{Abstract}

Helminthiases, a group of neglected tropical diseases, affect more than one billion people mainly in tropical and subtropical regions. Moreover, major intestinal protozoa have a significant impact on global public health. Albendazole (ABZ) is a broad-spectrum anthelmintic recommended by the World Health Organisation (WHO). However, drug resistance is emerging due to its widespread use. In order to tackle this problem, taking into account the spectacular results obtained with the organometallic derivatization of the antimalarial drug chloroquine, we have prepared, in this study, a series of new ferrocenyl and ruthenocenyl derivatives of the organic drug $\mathbf{A B Z}$ and assessed their activity against different helminths and protozoans, namely Trichuris muris, Heligmosomoides polygygrus, Schistosoma mansoni, Giardia lamblia, Haemonchus contortus and Toxoplasma gondii. The ferrocene-containing $\mathbf{A B Z}$ analogue $\mathbf{2 d}$ exhibited over $70 \%$ activity against $T$. muris adults in vitro at $200 \mu \mathrm{M}$ and no toxicity to mammalian cells $\left(\mathrm{IC}_{50}>100 \mu \mathrm{M}\right)$. H. polygyrus adults were not affected by any of the derivatives tested. Against T. gondii, the ferrocene-containing ABZ analogues 1a and $\mathbf{2 d}$ showed better in vitro activity than $\mathbf{A B Z}$ and low toxicity to the host cells. The activity of the analogous ruthenocenyl compound $\mathbf{2} \mathbf{b}$ against $S$. mansoni and $T$. gondii in vitro might be attributed to its toxicity towards the host cells rather than a specific antiparasitic activity. These results demonstrate that the derivatives show a species specific in vitro activity and the choice of the organometallic moieties attached to the organic drug is playing a very important role. Two of our organometallic compounds, namely $\mathbf{1 b}$ and $\mathbf{2} \mathbf{d}$, were tested in $T$. muris infected mice. At a 400 $\mathrm{mg} / \mathrm{kg}$ dose, the compounds showed moderate worm burden reductions but low worm expulsion rates. Overall, this work, which is one of the first studies reporting the potential of organometallic compounds on a very broad range of parasitic helminths and protozoan, is a clear confirmation of the potential of organometallic complexes against parasites of medical and veterinary importance.

KEYWORDS: anthelmintics; bioorganometallic chemistry; ferrocene; medicinal inorganic chemistry; medicinal organometallic chemistry. 


\section{INTRODUCTION}

Neglected tropical disease (NTDs) affect the poorest populations without adequate water and sanitation in tropical and subtropical regions. More than one billion people, which amounts to onesixth of the world's population, are affected by NTDs within 149 countries. ${ }^{1,2}$ Even though the morbidity exceeds the mortality, more than half a million deaths per year are caused by NTDs. ${ }^{3}$ Among NTDs, worm infection, or helminthiasis, has been the target of global elimination programs. ${ }^{4}$ Because of the large number of individuals affected, a resolution was passed by the World Health Organisation (WHO) in 2001 to control several helminth infections through preventive chemotherapy (PC), employing anthelmintics on populations at risk to prevent morbidity. 5,6 Considering the rapid re-infection following treatment and the possible development of resistance in species such as Trichuris or Schistosoma, there is an urgent need for research on novel and structurally different classes of potential anthelmintic drugs. Despite the urgency to develop new anthelmintics, the budget invested in this field of research is limited. The poorest population affected by NTDs is often living on less than US\$ 2 per day. Therefore, most of them cannot afford expensive medicines. ${ }^{6}$ Moreover, drugs in PC programs are donated in large scale treatment programs, which have mitigated effect. ${ }^{7}$ Concurrently, there is little motivation for the pharmaceutical industry to develop new drugs that might not provide return on huge research and development investment, making the discovery of new anthelmintics an even greater challenge.

Albendazole (ABZ, Figure 1) is an anthelmintic that was recommended by the WHO to treat soiltransmitted helminth infections. ${ }^{8} \mathbf{A B Z}$ shows a broad-spectrum of activity in domestic animals and was subsequently licensed for human use in $1982 .{ }^{9}$ Because of its effectiveness, safety and low price, ABZ is one of the main drugs used in PC programs. ${ }^{10}$ The excellent safety record of $A B Z$ is related to its mechanism of action, which involves selective binding to $\beta$-tubulin and disruption of microtubule polymerization. ${ }^{11}$ However, to the best of our knowledge, the exact manner how $\mathbf{A B Z}$ binds $\beta$ - 
tubulin is unclear. ${ }^{10}$ Nevertheless, there are several drawbacks associated with its use, such as poor drug absorption and the lack of water solubility. ${ }^{12}$ Importantly, its widespread use has resulted in reduced susceptibility of helminths of veterinary importance. ${ }^{13}$ Taking these effects into account is at the heart of the One Health initiative, ${ }^{14}$ as the development of drugs for human use can imply consequences for veterinary uses and vice-versa.

With this in mind, our research groups have started a program to derivatize $\mathbf{A B Z}$ with various organometallic moieties in order to evaluate their activity on various human and animal parasites, including, but not limited to, helminths. Organometallic compounds, which are defined as metal complexes containing at least one direct, covalent metal-carbon bond, have recently ${ }^{15,16,17}$ found numerous applications in medicinal chemistry, ${ }^{18,19,20,21}$ including against helminths ${ }^{22,23,24}$ and NTDs like schistosomiasis. ${ }^{3,25,26,27}$ For instance, Brocard, Biot and co-workers synthesized ferroquine (FQ, Figure 1), a ferrocenyl derivative of chloroquine (ACQ, Figure 1), which is currently undergoing phase II trials against malaria. ${ }^{28,29}$ It was demonstrated that ferroquine has an activity against both chloroquine-susceptible and chloroquine resistant $P$. falciparum. Ferrocene is a small, rigid, lipophilic molecule that can easily cross cellular membranes. ${ }^{30}$ These characteristics, along with its reversible electrochemical behavior, make ferrocenyl derivatives interesting candidates for biological applications and further drug design. For ferroquine or ferrocifen (Fc-TAM, Figure 1) - an anticancer drug analogue of tamoxifen (TAM, Figure 1) developed by the Jaouen group ${ }^{31}-$ the addition of a ferrocenyl moiety into a known organic drug has allowed a remarkable increase in activity compared to the parent organic compounds. Inspired by these successes, we herein report our findings concerning the antiparasitic activity of five ferrocenyl and two ruthenocenyl derivatives of $\mathbf{A B Z}$ with the aim to bypass drug-resistance pathways and/or to increase the potency and therapeutic scope of ABZ. The ruthenocenyl derivatives were synthesized because ferrocene and 
ruthenocene are isoelectronic and have a similar geometry and steric demand, yet they exhibit completely different electrochemical behavior and redox properties. ${ }^{20}$

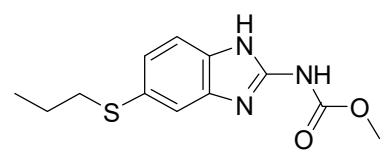

albendazole $(A B Z)$

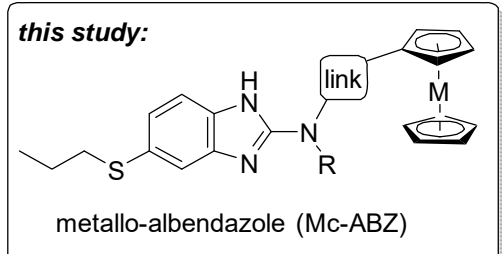

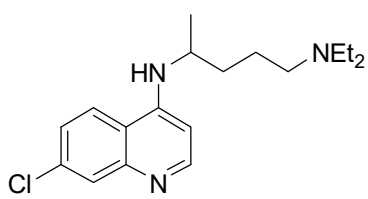

chloroquine $(\mathrm{CQ})$

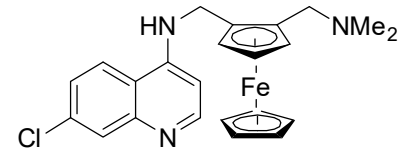

ferroquine (FQ)

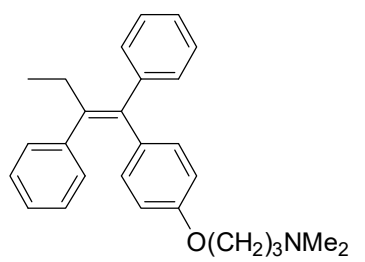

tamoxifen (TAM)

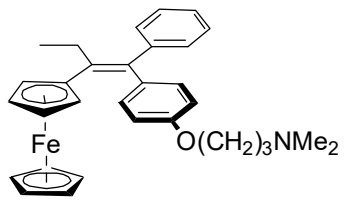

ferrocifen (Fc-TAM)

Figure 1. Structures of albendazole, chloroquine and tamoxifen and their metallocene derivatives.

\section{RESULTS AND DISCUSSION}

\section{Synthesis and characterization}

In this study, two strategies were used to synthesize ABZ analogues incorporating a metallocene moiety (Scheme 1). In the first strategy, (route A) the $\mathrm{N}$-methylcarbamate group was left untouched and the metallocenyl fragment added on the nitrogen. In the second (route B), the carbamate function was replaced by an acyl metallocene group (with various linkers). Compounds $\mathbf{1 a}, \mathbf{1 b}$ and 1c were prepared by direct treatment of $\mathbf{A B Z}$ with (ferrocenylmethyl)-trimethylammonium iodide, (ruthenocenylmethyl)-trimethylammonium iodide and (2-ferrocenylvinyl)methyltrimethylammonium iodide, respectively, with $\mathrm{K}_{2} \mathrm{CO}_{3}$ in acetonitrile using a similar synthetic method employed by Spiccia and co-workers. ${ }^{33}$ Route B started by the diethylenetriamine-mediated cleavage of the unactivated carbamate in $\mathbf{A B Z}$ to give $\mathbf{A B Z}-\mathbf{N H}_{\mathbf{2}}$ in good yield. ${ }^{34}$ Compound $\mathbf{A B Z}-\mathbf{N H}_{\mathbf{2}}$ was then converted into $\mathbf{2} \mathbf{a}-\mathbf{d}$ by treatment with the ferrocene- $(\mathbf{2} \mathbf{a}, \mathbf{c}, \mathbf{d})$ or ruthenocene- $\mathbf{2} \mathbf{2} \mathbf{b})$ containing carboxylic acid derivatives via a TBTU mediated amide coupling reaction. Comparing the activities of ruthenocenyl analogues $(\mathbf{1} \mathbf{b}, \mathbf{2} \mathbf{b})$ with their ferrocene counterparts $(\mathbf{1} \mathbf{a}, \mathbf{2} \mathbf{a})$ should allow detecting whether the iron-mediated redox properties are responsible for the anthelmintic activity. 
All newly synthesized compounds were unambiguously characterized by ${ }^{1} \mathrm{H},{ }^{13} \mathrm{CNMR}$ spectroscopy, IR spectroscopy and ESI mass spectrometry. The purity of individual compounds was confirmed by microanalysis. Details on synthesis and characterization of the complexes can be found in the Supporting Information.

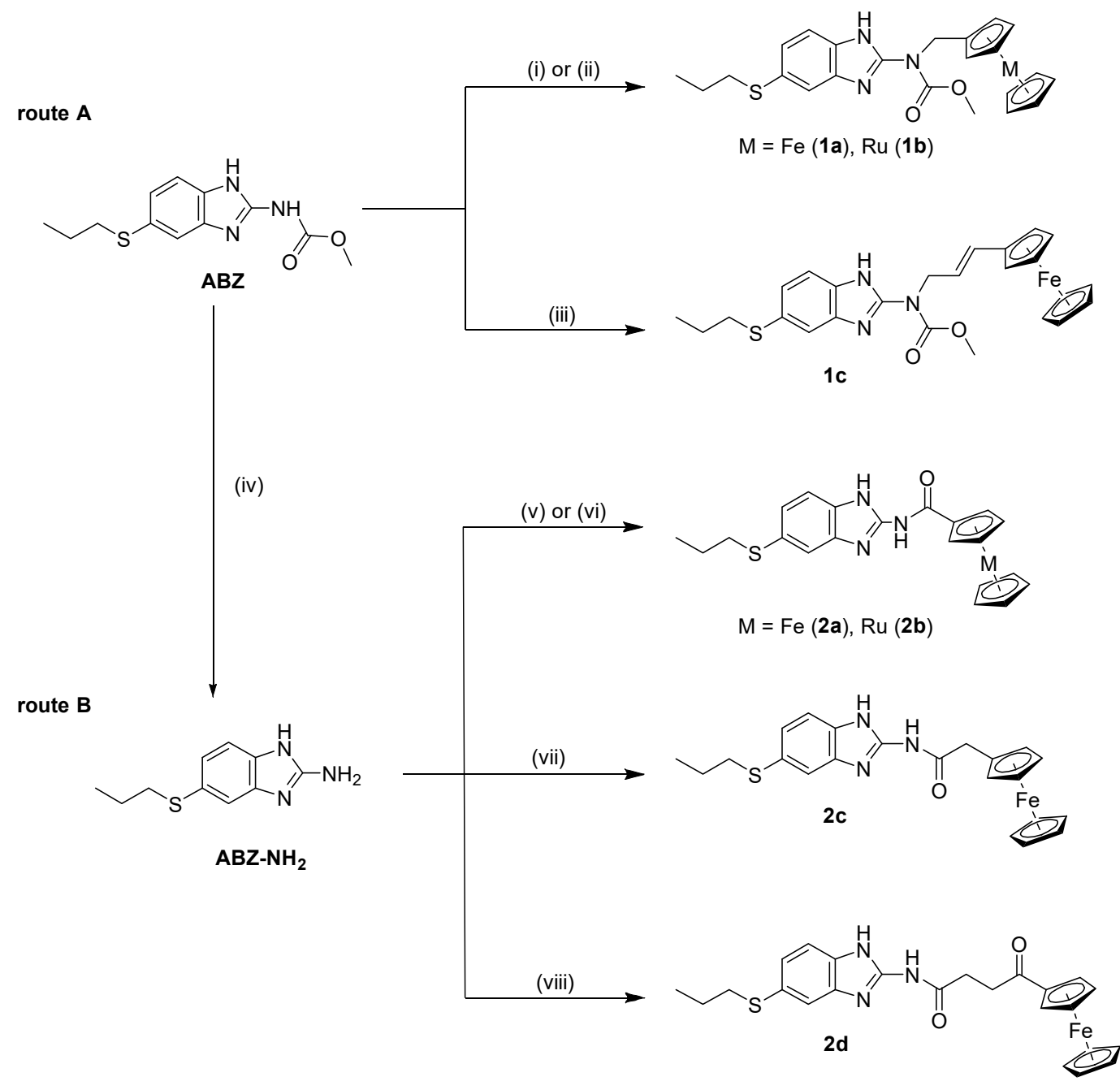

Scheme 1. Synthesis of the metallocene analogues of albendazole. Reagents and conditions: (i) (ferrocenylmethyl)-trimethylammonium iodide, $\mathrm{K}_{2} \mathrm{CO}_{3}$, dry $\mathrm{MeCN}, \quad 90^{\circ} \mathrm{C}$; (ii) trimethylammoniomethylruthenocene iodide, $\mathrm{K}_{2} \mathrm{CO}_{3}$, dry $\mathrm{MeCN}, 90^{\circ} \mathrm{C}$; (iii) (2-ferrocenylvinyl) methy-trimethylammonium iodide, $\mathrm{K}_{2} \mathrm{CO}_{3}$, dry $\mathrm{MeCN}, 90^{\circ} \mathrm{C}$; (iv) diethylenetriamine, $130^{\circ} \mathrm{C}$; (v) ferrocenecarboxylic acid, TBTU, DIPEA, dry DMF; (vi) ruthenocenecarboxylic acid, TBTU, DIPEA, dry DMF; (vii) ferroceneacetic acid, TBTU, DIPEA, dry DMF; (viii) 3-Ferrocenoylpropionic acid, TBTU, DIPEA, dry DMF. 
Additionally, complexes $\mathbf{1 a}, \mathbf{1 b} \mathbf{1} \mathbf{1 c}$ were characterized using single-crystal X-ray crystallography

(Figure 2). Details on the acquisition of the structures can be found in the Supporting Information.

A

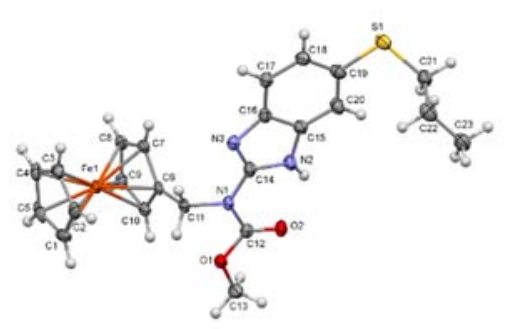

B

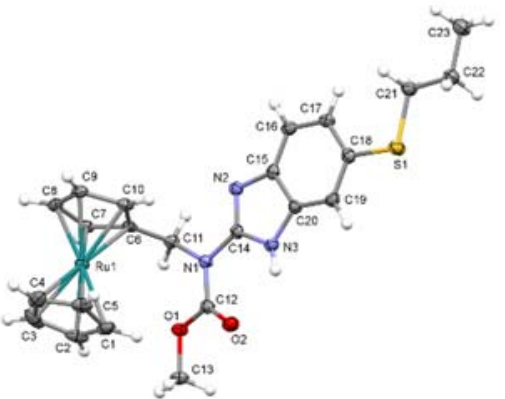

C

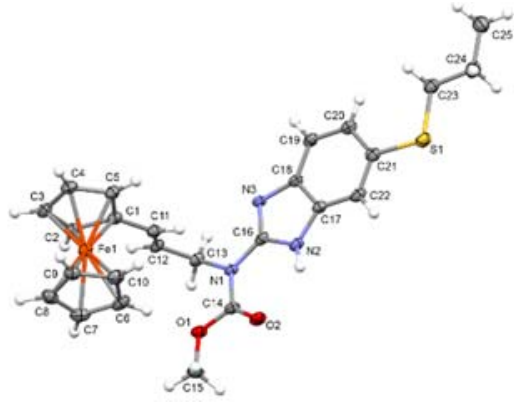

Figure 2. A: molecular structure of 1a; B: molecular structure of $\mathbf{1 b}$; C: molecular structure of 1c. The thermal ellipsoids are drawn at the $30 \%$ probability level.

\section{Stability in human plasma}

In order to assess the stability of our metallocene-containing $\mathbf{A B Z}$ derivatives under simulated biological conditions, we first studied their behavior in human plasma. Human plasma stability is a crucial parameter of the stability profile for drug discovery, as compounds unstable in plasma are generally not suitable drug candidates, with the exception of some prodrugs or antedrugs. ${ }^{35}$ In order to do so, a rapid, accurate and economic method based on HPLC and LC-MS technique was chosen, as recently reported by our group. ${ }^{26,36}$ Caffeine, which is known to be stable in human plasma, was chosen as an internal standard. After incubation in human plasma at $37^{\circ} \mathrm{C}$ for various times, methanol was added to quench the plasma solution. Afterwards, the recovery of the internal standard, the test compound and the eventual metabolites was performed by liquid extraction with dichloromethane. The obtained residue was analyzed by RP-HPLC (See Supporting Information for details) and the results of these analyses are gathered in Figure 3. $\mathbf{A B Z}$ and $\mathbf{A B Z}-\mathbf{N H}_{\mathbf{2}}$ proved to be relatively stable after $24 \mathrm{~h}$ incubation in human plasma - they are decomposed by only $2 \%$ and $17 \%$, respectively. The metallocene-containing $\mathbf{A B Z}$ derivatives showed moderate to good stability after $6 \mathrm{~h}$ but significant decay was observed after $24 \mathrm{~h}$. The ferrocene-containing compound $\mathbf{2 d}$ displayed the best stability of the derivatives in human plasma after $24 \mathrm{~h}$, with only $23 \%$ degradation. 
Compound $\mathbf{2 b}$ showed the second best stability since it only decomposed by $26 \%$ after $24 \mathrm{~h}$ incubation. Nearly $50 \%$ degradation was measured after $24 \mathrm{~h}$ for compounds $1 \mathrm{a}-\mathbf{1 c}$ and $\mathbf{2 a}$.

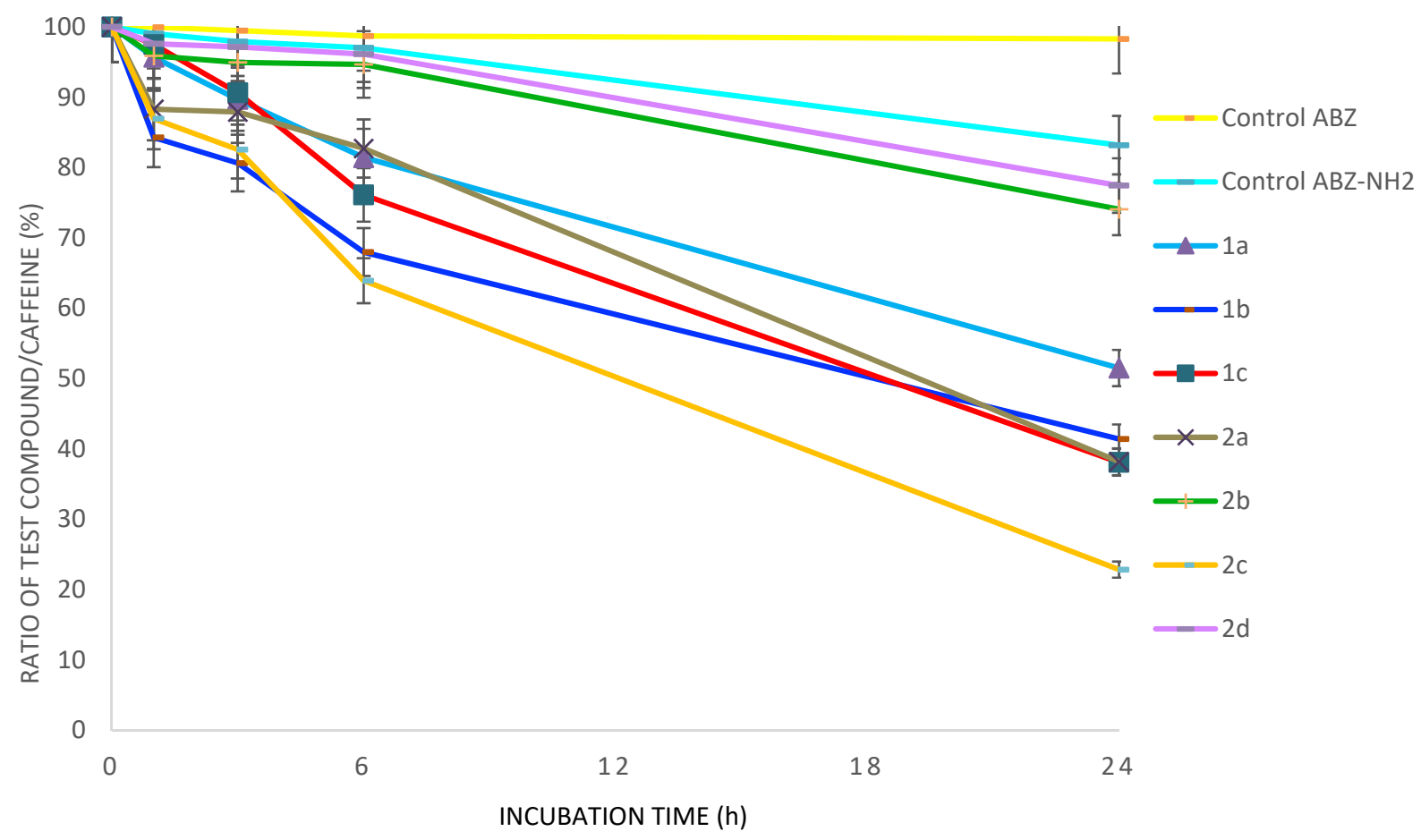

Figure 3. Stability of the metallocene-containing $\mathbf{A B Z}$ in human plasma. The ratio of the test compound peak area to the internal standard peak area was set as $100 \%$ at $t=0$. This ratio was plotted with regards to the time of incubation.

Compound $\mathbf{2 c}$ was shown to decompose at a highest rate (ca. $77 \%$ release after $24 \mathrm{~h}$ incubation). The following order for stability in human plasma can be made from the most stable to the least stable: $\mathbf{2} \mathbf{d}>\mathbf{2} \mathbf{b}>\mathbf{1 a}>\mathbf{1} \mathbf{b}>\mathbf{1 c} \approx \mathbf{2} \mathbf{a}>\mathbf{2 c}$. We thought the electron-withdrawing functional group attached to the metallocene, as carbonyl, might help to stabilize the organometallic derivatives. To gain further insight on the nature of the decomposition products, LC-MS analyses were performed. In the case of $\mathbf{1 b}$, the main degradation compound was identified to be the result from the oxidation of $\mathbf{1 b}$. Hypothesizing that the oxidation site would be the sulfur atom, $\mathbf{1} \mathbf{b}-\mathbf{O x}$ was synthetized from ABZ by a two-step oxidation/substitution sequence (Scheme 2). Its identity as the degradation product from $\mathbf{1 b}$ was then confirmed by measuring its retention times under the same HPLC conditions (see Supporting Information). As shown in Scheme 2, the sulfoxide analogue 2d-Ox was 
also synthetized by acylation of $\mathbf{A B Z}-\mathbf{N H}_{\mathbf{2}}-\mathbf{O x}$ that was itself obtained from $\mathbf{A B Z}-\mathbf{O} \mathbf{x}$. As expected, $\mathbf{2 d -}$

Ox was confirmed to be the major metabolite of $\mathbf{2} \mathbf{d}$ in human plasma. The metabolites of $\mathbf{A B Z}$ and $\mathbf{A B Z}-\mathbf{N H}_{2}$ were also confirmed to be $\mathbf{A B Z}-\mathbf{O} \mathbf{x}$ and $\mathbf{A B Z}-\mathbf{N H}_{\mathbf{2}}-\mathbf{O x}$, respectively (see Supporting Information). ${ }^{37}$ The metabolites of $\mathbf{1 a}, \mathbf{1} \mathbf{c}, \mathbf{2} \mathbf{a}$ and $\mathbf{2} \mathbf{b}$ were not unambiguously identified, yet, the mass spectra are consistent with oxidized species, presumably also occurring on the sulfur atom. For compound $\mathbf{2 c}$, despite its rather moderate stability, no degradation peak could be found by HPLC and LC-MS. This study is an excellent indication that these metallocene-containing $\mathbf{A B Z}$ derivatives were exclusively metabolized to their oxidized species, as neither peaks corresponding to the free metal complexes nor to released $\mathbf{A B Z}$ could be observed.

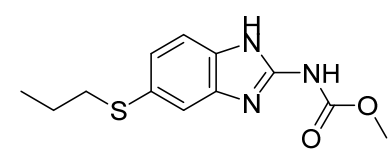

ABZ
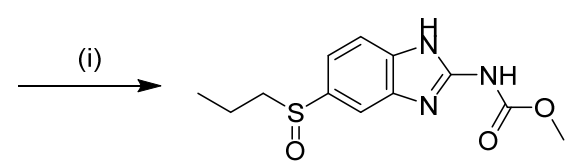

ABZ-Ox

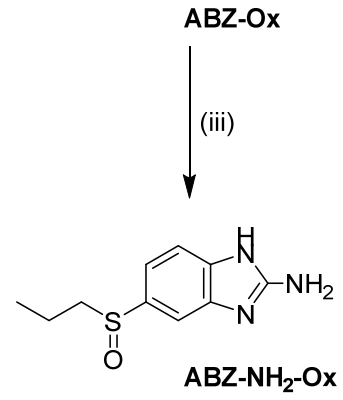

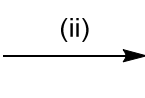

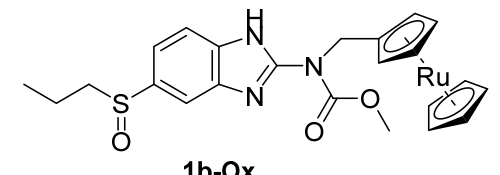

1b-Ox

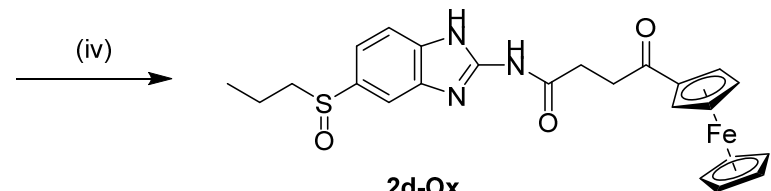

Scheme 2. Synthesis of the oxidized analogues of $\mathbf{1 b}$ and $\mathbf{2 d}$. Reagents and conditions: (i) $37 \% \mathrm{H}_{2} \mathrm{O}_{2}$, glacial acetic acid; (ii) trimethylammoniomethylruthenocene iodide, $\mathrm{K}_{2} \mathrm{CO}_{3}$, dry $\mathrm{MeCN}, 90^{\circ} \mathrm{C}$; (iii) diethylenetriamine, $130^{\circ} \mathrm{C}$; (iv) 3-Ferrocenoylpropionic acid, TBTU, DIPEA, dry DMF.

\section{Antiparasitic activities}

A broad spectrum screening against a range of helminths was conducted. In a One Health approach, the chosen panel of parasites included species able to colonize both human and animals: Heligmosomoides polygygrus (rodents), Trichuris muris (mice, analogous to the human parasite Trichuris trichiura), Schistosoma mansoni (human), Haemonchus contortus (ruminants such as sheep) as well as protozoan parasites that can affect humans: Giardia lamblia and Toxoplasma gondii. 
Helminths. Results obtained when testing the derivatives against adult species of the hookworm $\mathrm{H}$. polygygrus, the whipworm T. muris and the schistosome S. mansoni in vitro are summarized in Table 1. Interestingly, compound $\mathbf{A B Z}-\mathbf{N H}_{\mathbf{2}}$ was the most active compound showing high activity against all three species tested at concentrations of 100-200 $\mu \mathrm{M}$. Against S. mansoni, $\mathbf{A B Z}-\mathbf{N H}_{\mathbf{2}}$ achieved even death of all worms at $200 \mu \mathrm{M}$. On the other hand, $\mathbf{A B Z}$, the drug of choice for hookworm and whipworm infections lacked activity against all 3 species tested confirming previous findings. ${ }^{38}$ Compounds $\mathbf{1} \mathbf{b}$ and $\mathbf{2} \mathbf{d}$ showed activity (resulting in reduced motility) against $T$. muris at the highest concentration tested while $\mathbf{2} \mathbf{b}$ affected S. mansoni. None of the compounds showed activity against H. polygyrus adults. In the in vitro cytotoxicity assay using L6 rat cells, compounds $\mathbf{2 a}$ and $\mathbf{2} \mathbf{d}$ were found to be the least toxic against mammalian cells.

Table 1. in vitro activity of derivatives against Heligmosomoides polygygrus, Trichuris muris and Schistosoma mansoni

\begin{tabular}{|c|c|c|c|c|c|c|c|c|}
\hline \multirow{2}{*}{ Compound } & \multicolumn{3}{|c|}{ T. muris adult } & \multicolumn{2}{|c|}{ H. polygygrus adult } & \multicolumn{2}{|c|}{ S. mansoni adult } & \multirow{2}{*}{$\begin{array}{c}\begin{array}{c}\text { Cytotoxic L6 } \\
\text { cells }^{\mathrm{a}}\end{array} \\
\mathrm{IC}_{50}(\mu \mathrm{M})\end{array}$} \\
\hline & $200 \mu \mathrm{M}$ & $100 \mu \mathrm{M}$ & $10 \mu \mathrm{M}$ & $200 \mu \mathrm{M}$ & $100 \mu \mathrm{M}$ & $200 \mu \mathrm{M}$ & $100 \mu \mathrm{M}$ & \\
\hline $1 a$ & $31.4(9.3)$ & & & $38.3(22.4)$ & & $48.9(11.8)$ & & 14.7 \\
\hline $1 b$ & $74.5(9.3)$ & $23(11.8)$ & & $46.7(11.8)$ & & $57.1(12.5)$ & & 4.3 \\
\hline 1c & $35.3(37.5)$ & & & 41.7 (9.3) & & $56.8(18.6)$ & & 18 \\
\hline $2 a$ & $19.6(9.3)$ & & & $40.0(0.0)$ & & $26.5(0.0)$ & & $>100 \mu \mathrm{M}$ \\
\hline $2 b$ & 11.8 (12.5) & & & $31.7(9.3)$ & & $73.4(9.3)$ & $24.8(12.5)$ & 3.8 \\
\hline $2 c$ & 27.5 (9.3) & & & $30.0(0.0)$ & & $20.3(12.5)$ & & 27 \\
\hline 2d & 78.4 (9.3) & $19.2(0.0)$ & & $46.7(11.8)$ & & $59.2(11.8)$ & & $>100 \mu \mathrm{M}$ \\
\hline$A B Z$ & $19.6(9.3)$ & & & $28.3(9.3)$ & & $56.8(18.6)$ & & 2 \\
\hline ABZ-NH2 & $90.2(9.3)$ & $84.6(11.8)$ & $40.0(12.5)$ & $70.0(0.0)$ & $33.3(14.4)$ & $100(0.0)$ & $52.8(14.4)$ & 28.9 \\
\hline
\end{tabular}

\footnotetext{
a $2 \mathrm{~h}$ after adding Resazurin dye. Table reports mean activity values (\%) and standard deviation (SD).
}

Given these promising in vitro findings, compounds $\mathbf{A B Z}-\mathbf{N H}_{\mathbf{2}}, \mathbf{1} \mathbf{b}$ and $\mathbf{2} \mathbf{d}$ underwent testing in $T$. muris infected mice. At a $400 \mathrm{mg} / \mathrm{kg}$ dose compounds showed moderate worm burden reductions 
but, unfortunately, only low worm expulsion rates (Table 2). All compounds were well tolerated by mice despite the low $\mathrm{IC}_{50}$ of $\mathbf{1 b}$ in the cytotoxicity $\mathrm{L} 6$ assay. 
Table 2. Activity of $1 \mathrm{~b}$ and two derivatives in $T$. muris infected mice when administered at 400 $\mathrm{mg} / \mathrm{kg}$

\begin{tabular}{c|ccccc} 
Compound & Mice cured/investigated & $\begin{array}{c}\text { Mean number of } \\
\text { worms in intestine } \\
\text { (SD) }\end{array}$ & $\begin{array}{c}\text { Mean number of } \\
\text { worms in stool } \\
\text { (sd) }\end{array}$ & $\begin{array}{c}\text { Worm burden } \\
\text { reduction* }\end{array}$ & $\begin{array}{c}\text { Worm expulsion } \\
\text { rate } * *\end{array}$ \\
\hline Control & $0 / 4$ & $114.0(9.3)$ & $0.5(0.6)$ & -- & -- \\
ABZ-NH2 & $0 / 4$ & $48.8(5.7)$ & $0.3(0.5)$ & 57 & 0,5 \\
1b & $0 / 4$ & $36.3(2.2)$ & $2.0(1.8)$ & 68,1 & 5,2 \\
2d & $0 / 4$ & $47.5(11.2)$ & $0.8(0.1)$ & 58,1 & 1,6 \\
\hline
\end{tabular}

* decrease in mean worm burden of treatment groups compared to the mean burden of the control group

** Mean number of worms expelled within 72 hours after treatment

All nine derivatives, including $\mathbf{A B Z}$, were tested against $H$. contortus $x \mathrm{~L} 3 \mathrm{~s}$ (a helminth affecting ruminants such as sheep) in the whole-organism assay. The parent compound, $\mathbf{A B Z}$, and its derivatives $\mathbf{A B Z}-\mathbf{N H}_{2}$ and $\mathbf{2 a}$ all decreased $\mathrm{L} 4 \mathrm{~s}$ development over 7 days using $100 \mu \mathrm{M}$ of each compound. ABZ, ${ }^{39}$ which has previously been evaluated, fully inhibited L4 development at this concentration. Compounds $\mathbf{A B Z}-\mathbf{N H}_{2}$ inhibited L4 development by $35.8 \%(p=<0.0001)$, whereas compound 2 a reduced this development by $19.1 \%(p=0.001$; Figure $4 \mathrm{~A})$. Dose-response evaluations estimated the potencies of individual compounds on $x L 3$ motility after $72 \mathrm{~h}$ (Figure 4B). An inhibition of $x$ L3 motility was observed for compounds $\mathbf{1 b}$ and $\mathbf{2 b}$, but no greater than $27.2 \%$ inhibition was observed at $100 \mu \mathrm{M}$, and $\mathrm{ABZ}$ exhibited xL3 motility by $16.0 \%$. The two reference compounds, monepantel and moxidectin, exhibited the expected reduction in XL3 motility (> 85.0\%). All six other compounds were ineffective at the highest concentration tested (100 $\mu \mathrm{M})$.

A

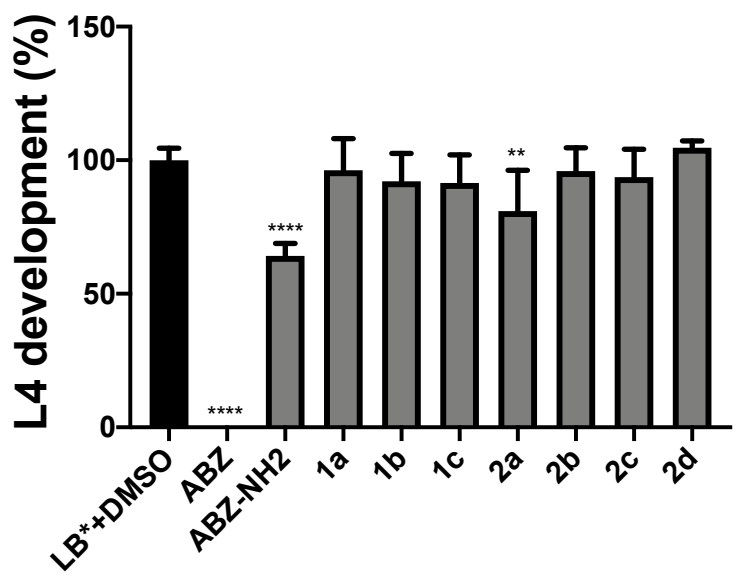

Compounds $(100 \mu \mathrm{M})$
B

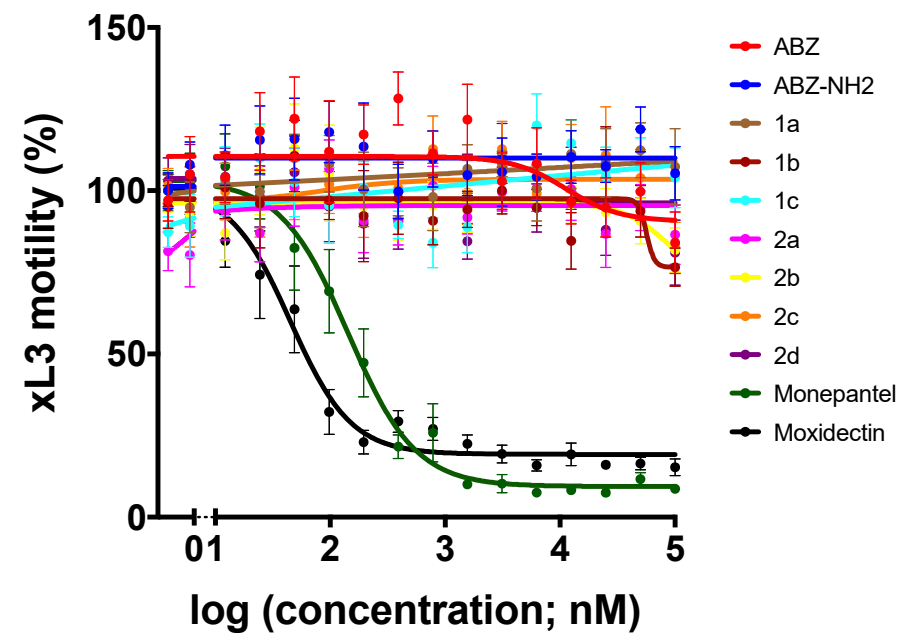

Figure 4: In vitro activity of $A B Z$ derivatives against exsheathed third-stage larvae (xL3) $H$. contortus in vitro. (A) Development of $x \mathrm{~L} 3$ to fourth-stage larvae (L4) at $100 \mu \mathrm{M}$ after 7 days. (B) 
Dose-response curves of the effects of 9 compounds and two reference compounds (monepantel and moxidectin) on the inhibition of motility at $72 \mathrm{~h}$. Data points represent three independent experiments conducted in triplicate; the mean $\pm S$ EM. ${ }^{* *}$ and ${ }^{* * * *}$ denote for $p$ values of 0.001 and $<0.0001$, respectively.

Giardia lamblia. As expected, cultivation in the presence of 0.1 and $1 \mu \mathrm{M}$ ABZ resulted in complete inhibition of resazurin reduction, indicating loss of viability in $100 \%$ of all parasites, while the presence of $0.01 \mu \mathrm{M} \mathrm{ABZ}$ caused a $70 \%$ reduction of viability when compared to the solvent control (Figure 5). Compound $\mathbf{A B Z}-\mathbf{N H}_{\mathbf{2}}$ was largely ineffective at all three concentrations, while for compound 1a a reduction in viability to approximately $60 \%$ was measured at $0.01 \mu \mathrm{M}$, but viability was increased at higher concentrations. For $\mathbf{1 c}, \mathbf{2 a}$, and $\mathbf{2 c}$, the presence of these compounds impaired viability to levels of $40-60 \%$, except for $\mathbf{2 d}$, which resulted in a reduction of $>95 \%$ when 1 $\mu \mathrm{M}$ was applied. Compounds $\mathbf{1} \mathbf{b}$ and $\mathbf{2} \mathbf{b}$ were ineffective under these conditions.

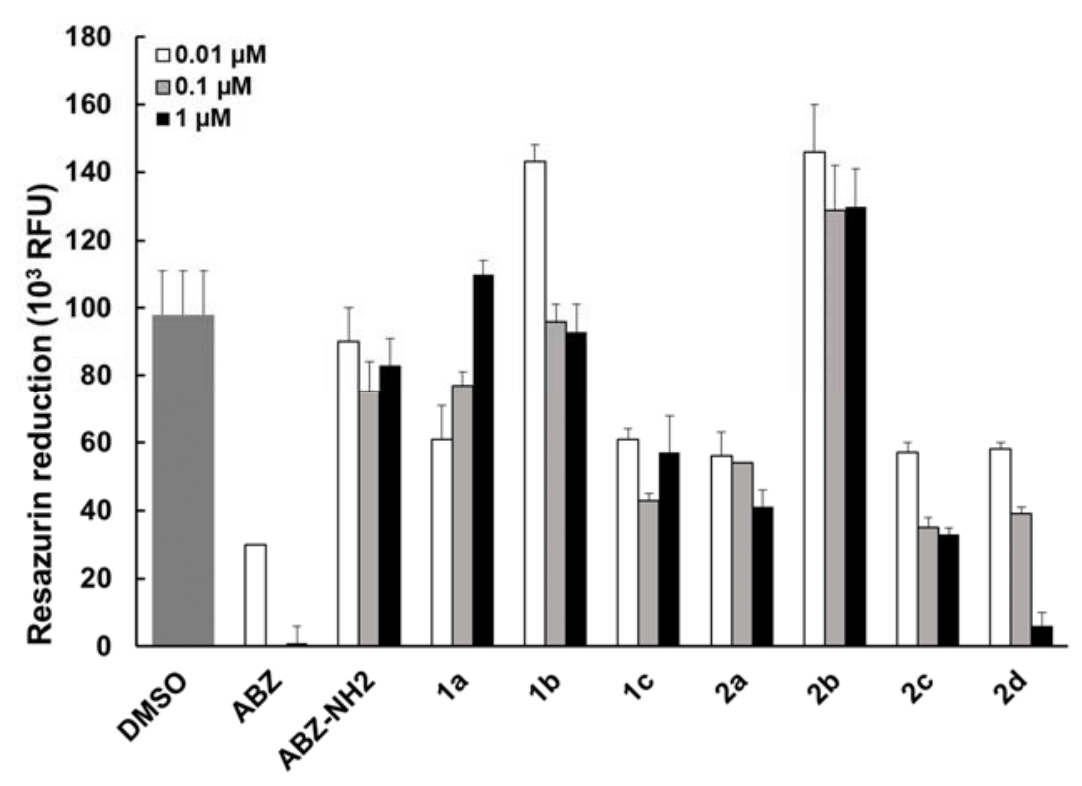

Figure 5. In vitro screening of G. lamblia trophozoites. The viability of G. lamblia trophozoites is measured by Resazurin assay. Compounds were applied at 1, 0.1 or $0.01 \mu \mathrm{M}$ for a period of $72 \mathrm{~h}$. 
Toxoplasma gondii. As can be seen in Figure 6, compounds $\mathbf{A B Z}, \mathbf{A B Z}-\mathbf{N H}_{\mathbf{2}}, \mathbf{1 a}, \mathbf{2} \mathbf{d}$ and $\mathbf{2 b}$ severely impair T. gondii proliferation when applied at $10 \mu \mathrm{M}$, and when applied at lower concentrations, a clear dose-dependent effect is evident. However, the inhibition seen with $\mathbf{2} \mathbf{b}$ and $\mathbf{2} \mathbf{d}$ at $10 \mu \mathrm{M}$ can be partially attributed to the impact these compounds have against HFF host cells (see below).

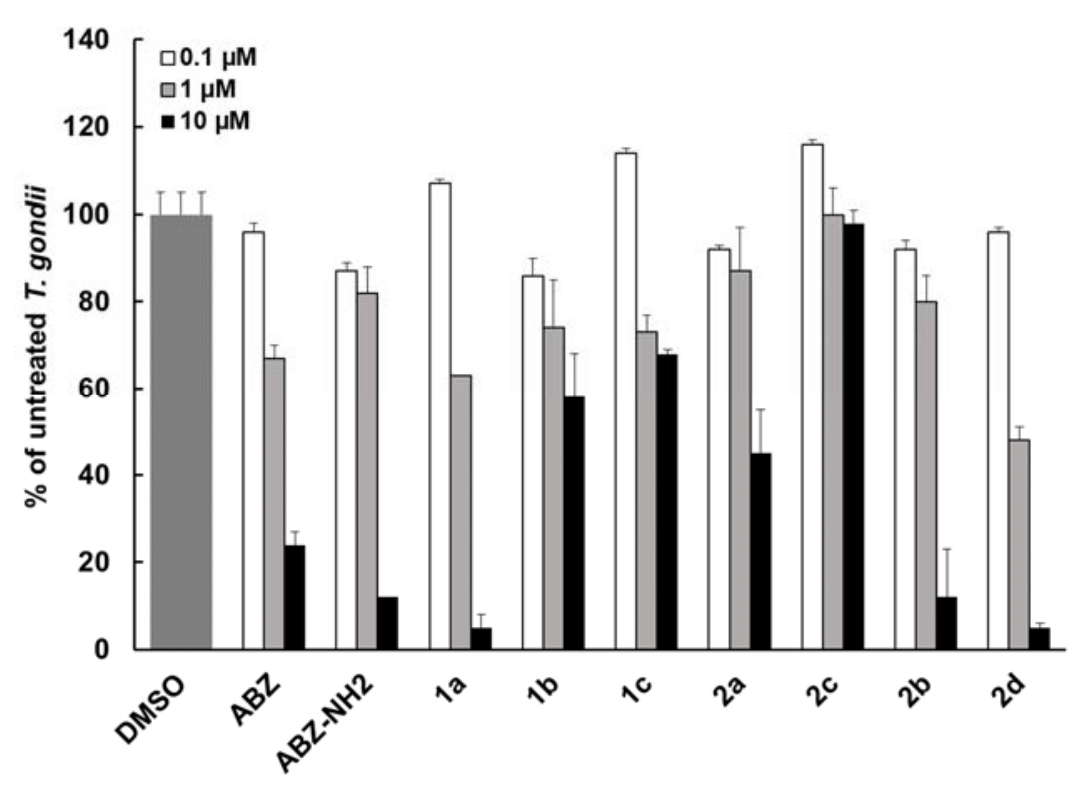

Figure 6. In vitro screening of $T$. gondii $\beta$-gal tachyzoites cultured in HFF host cells. The proliferation of $T$. gondii tachyzoites was quantified by measuring $\beta$-galactosidase activity. Compounds were applied at $0.1,1$ or $10 \mu \mathrm{M}$ for a period of $72 \mathrm{~h}$. The compound activity is shown as percentage in relation to the DMSO controls which represent $100 \%$ of parasite growth.

In order to discriminate between the activity on the parasite and on the host cell, the toxicity of the compounds was also evaluated on HFF cells alone (Figure 7). With the exception of compound $\mathbf{2 b}$ and $\mathbf{2} \mathbf{d}$ at the highest concentration, none of these compounds presented cytotoxicity against HFF monolayers. Thus, with the exception of $\mathbf{2} \mathbf{b}$, and $\mathbf{2} \mathbf{d}$, the effects seen against $T$. gondii can be attributed to mechanisms that are targeting the parasites. 


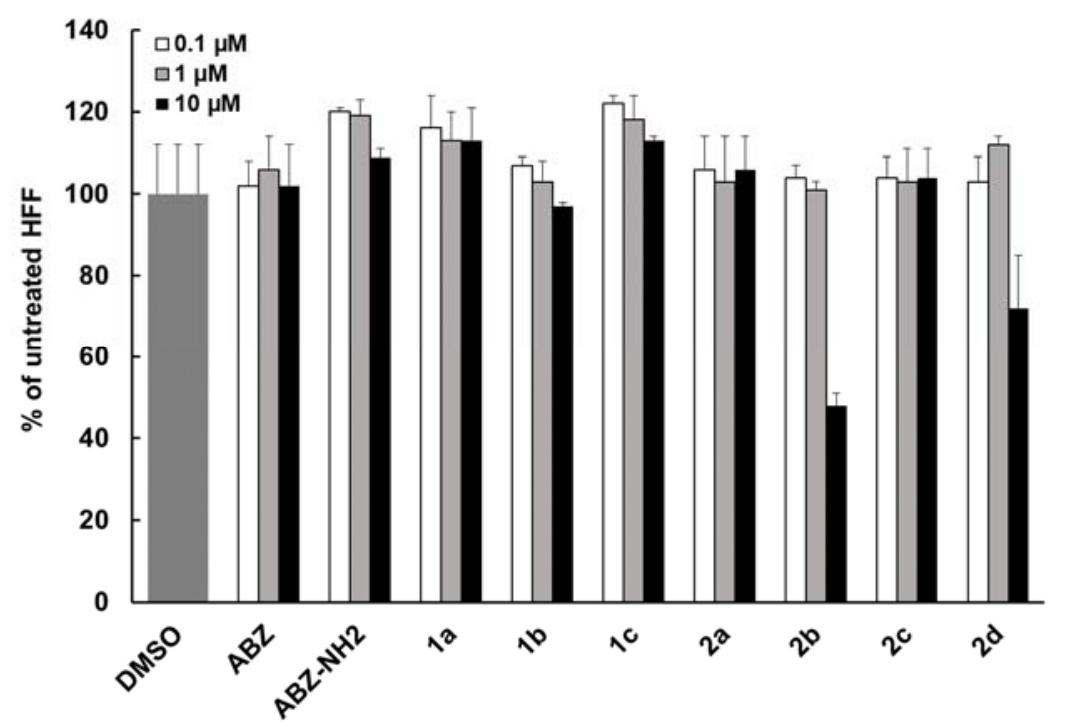

Figure 7. In vitro screening of non-infected HFF host cells. The viability of HFF was quantified by measurement of resazurin reduction. Compounds were applied at $0.1,1$ or $10 \mu \mathrm{M}$ for a period of 72 h. The viability of HFF is shown as percentage in relation to the DMSO controls which represent $100 \%$ viability.

\section{CONCLUSIONS}

In this study, we synthesized and characterized a series of ferrocene- and ruthenocene-containing organometallic analogues of the anthelmintic drug ABZ. In human plasma, the metallocenecontaining $A B Z$ derivatives showed moderate to good stability after $6 \mathrm{~h}$, with ferrocenyl derivative $\mathbf{2 d}$ displaying the best stability after $24 \mathrm{~h}$ incubation. As for $\mathbf{A B Z}$, the major metabolites for the compounds turned out to be the corresponding sulfoxides, as demonstrated by the syntheses of the oxidized forms of $\mathbf{1 b}$ and $\mathbf{2} \mathbf{d}$, namely $\mathbf{1} \mathbf{b}-\mathbf{O} \mathbf{x}$ and $\mathbf{2} \mathbf{d}-\mathbf{O} \mathbf{x}$. These findings are a good indication that the active forms were not due to the release of $\mathbf{A B Z}$ or of a free organometallic moiety. In vitro activity of the metallocene-containing $\mathbf{A B Z}$ derivatives against $H$. polygygrus adult, $T$. muris adult and $S$. mansoni adult showed that $\mathbf{1} \mathbf{b}$ and $\mathbf{2 d}$ displayed over $70 \%$ activity against $T$. muris at $200 \mu \mathrm{M}$. Compound $\mathbf{2 b}$ also showed over $70 \%$ activity against S. mansoni at the highest concentration. Encouraged by these promising in vitro results, compounds $\mathbf{1 b}$ and $\mathbf{2} \mathbf{d}$ underwent testing in T. muris infected mice at a single dose of $400 \mathrm{mg} / \mathrm{kg}$ and exhibited interesting, albeit moderate, worm burden reductions and worm expulsion rates. However, the anthelmintic activity against $H$. contortus was negligible for most compounds, compared to the high efficiency of ABZ itself. Although not better than $\mathbf{A B Z}$, the activity of four analogues $(\mathbf{1 c}, \mathbf{2 a}, \mathbf{2} \mathbf{c}$ and $\mathbf{2 d}$ ) against protozoan 
G. lamblia was also promising. Finally, against the protozoan $T$. gondii, compounds $\mathbf{1 a}$ and $\mathbf{2 d}$ showed better activity than $\mathbf{A B Z}$ at $1 \mu \mathrm{M}$, while they mostly showed cytotoxic effects on not infected HFF host cells at $10 \mu \mathrm{M}$. This suggests that the ferrocene-containing compounds $\mathbf{1 a}$ and $\mathbf{2 d}$ are promising anti-toxoplasma candidates for in vivo evaluation. Overall, this study demonstrates that organometallic $\mathbf{A B Z}$ derivatives can outperform $\mathbf{A B Z}$ as interesting leads for further development not only as a new class of anthelmintic agents but also against other types of parasites due to the attached organometallic portions. Further studies would be warranted to be better elucidate the mechanism of action of these organometallic derivatives, investigated the effect on metal-specific properties, like ROS production, redox activation, and lipophilicity, etc. Nonetheless, these compounds present excellent starting points that help advance the field of organometallic medicinal chemistry in the area of neglected tropical diseases.

\section{MATERIALS \& METHODS}

\section{In vitro assays on $H$. polygyrus and $T$. muris adult worms}

Female NMRI mice were infected with $88 \mathrm{H}$. polygyrus L3. Two weeks post-infection, mice were dissected. Seven weeks post-infection of female C57BL/6NRj, T. muris adult worms were collected from the intestines. Three to four adult worms were placed in each well of a 24-well plate and exposed to the test drugs at concentrations ranging from 200-10 $\mu \mathrm{M}$. The highest percentage of DMSO used in the assays served as a control. The assay was conducted in duplicate. Worms were incubated at $37^{\circ} \mathrm{C} / 5 \% \mathrm{CO}_{2}$ up to $72 \mathrm{~h}$, after which the drug effect was evaluated. The condition of the worms was microscopically evaluated using a viability scale from 3 (normal activity) to 0 (dead) following stimulation with $500 \mu \mathrm{l}$ hot water $\left(\approx 80^{\circ} \mathrm{C}\right)$.

\section{In vitro assays on adult S. mansoni}

Mice were dissected seven weeks post-infection with 100 cercariae. At least three worms (both sexes) were incubated with 200 and $100 \mu \mathrm{M}$ of the derivatives in $2 \mathrm{ml}$ RPMI 1640 (Gibco, USA) supplemented with $5 \%(\mathrm{v} / \mathrm{v}) \mathrm{FCS}$ and $1 \%(\mathrm{v} / \mathrm{v})$ pen-strep at $37^{\circ} \mathrm{C} / 5 \% \mathrm{CO}_{2}$ for 72 hours $\mathrm{h}$. Details on the viability scale used for scoring are published elsewhere. ${ }^{40}$

\section{Animals}

Three-week-old female C57BL/6NRj mice were purchased from Janvier Labs (Le Genest-Saint-Isle, France) and female mice (NMRI strain; age 3 weeks-old; weight ca. 20-22 g) were purchased from 
Charles River, Germany. Rodents were kept under environmentally-controlled conditions (temperature: $25^{\circ} \mathrm{C}$, humidity: $70 \%$, light/dark cycle $12 \mathrm{~h} / 12 \mathrm{~h}$ ) with free access to water (municipal tap water supply) and rodent food. Rodents were allowed to acclimatize for 1 week before infection. The current study was approved by the local veterinary agency, based on Swiss cantonal and national regulations (permission no. 2070).

\section{T. muris in vivo studies}

C57BL/6NRj mice were orally infected with 200 embryonated T. muris eggs. Mice were immunosuppressed with dexamethasone $(1 \mathrm{mg} / \mathrm{ml})$ in their drinking water until 2 days prior to treatment. At 42 days post-infection, the stool was collected and checked for the presence of eggs. The compounds were administered orally at a single oral dose of $400 \mathrm{mg} / \mathrm{kg}$. Four untreated mice served as controls. The stool was collected from 0-72 $\mathrm{h}$ post-treatment from each mouse to determine the worm expulsion rate. Six to seven days post-treatment, animals were killed, the intestine was dissected and adult worms were collected and counted.

\section{Cytotoxicity testing against $L 6$ cells}

Rat skeletal myoblast L6 cells were exposed to the test drugs. Podophyllotoxin (with $0.05 \mu \mathrm{g} / \mathrm{ml}$ as highest concentration) was used as a positive control. After a $70-\mathrm{h}$ incubation at $37^{\circ} \mathrm{C} / 5 \% \mathrm{CO}_{2}$, resazurin dye (Alamar Blue) was added and the plates were incubated for an additional 2 hours Fluorescence and the cytotoxic concentration (CC50) were measured at $530 \mathrm{~nm}$ excitation and 590 $\mathrm{nm}$ emission wavelength using a SpectraMax M2 (Molecular Device, Sunnyvale CA, USA; Softmax version 5.4.6). Experiments were conducted in duplicate and repeated once.

\section{In vitro assessment of inhibitory activity on larval development of Haemonchus contortus}

All derivatives and $\mathbf{A B Z}$ were individually tested for their ability to inhibit the motility of exsheathed third-stage larvae $(x \mathrm{~L} 3)$ of $H$. contortus and the development of these larvae to fourth-stage larvae (L4) using established assays. ${ }^{41}$ Compounds were tested in an 18 point, two-fold dilution series, starting at $100 \mu \mathrm{M}$. The reduction in $x L 3$ motility was measured at $72 \mathrm{~h}$, and inhibition of $L 4$ development was evaluated after 7 days. For the xL3 motility assay, monepantel (Zolvix, Elanco Animal Health, Australia) and moxidectin (Cydectin, Virbac, France) were included as positive controls. Culture medium, i.e. Luria Bertani broth supplemented with $100 \mathrm{IU} / \mathrm{ml}$ of penicillin, 100 $\mu \mathrm{g} / \mathrm{ml}$ of streptomycin and $0.25 \mu \mathrm{g} / \mathrm{ml}$ of amphotericin B (Gibco, Thermofisher Scientific, USA), with 
matched concentrations of DMSO (0.25\%), served as negative controls in the assays. Each assay has three technical replicates and was repeated three times on different days. For each compound, dose-response curves were determined by fitting the log ${ }_{10}$-transformed concentration to a variable slope four-parameter model. The data were analysed with reference to the negative controls using non-parametric one-way ANOVA and Dunnett's multiple comparison tests employing the GraphPad Prism (v.8.3.1).

\section{In vitro activity against the protozoan Giardia lamblia}

G. lamblia trophozoites were grown under anaerobic conditions in $10 \mathrm{ml}$ culture tubes (Nunc, Roskilde, Denmark) as described. ${ }^{42}$ Cultures with adherent confluent trophozoite lawns were incubated on ice for $15 \mathrm{~min}$, suspended motile trophozoites were counted in a Neubauer chamber at $200 \times$ magnification), and were distributed into 96 well plates in $0.2 \mathrm{ml}$ Keister-medium containing 1000 trophozoites per well in the presence of the compounds (0.01, 0.1 or $1 \mu \mathrm{M}$, all in triplicates) dissolved in DMSO (10 mM stock solutions) or with the corresponding DMSO solvent control. They were then cultured for $72 \mathrm{~h}$ at $37^{\circ} \mathrm{C}$ in an anaerobic chamber $\left(80 \% \mathrm{~N}_{2}, 10 \% \mathrm{H}_{2}, 10 \% \mathrm{CO}_{2}\right.$. Subsequently, plates were centrifuged ( $2 \mathrm{~min}, 1000 \times \mathrm{g}$ ), medium was removed, and cells were washed once with PBS containing $1 \mathrm{~g} / \mathrm{l}$ glucose. Then, PBS-glucose containing $10 \mathrm{mg} / \mathrm{l}$ resazurin was added, and plates were incubated for up to $5 \mathrm{~h}$ at $37^{\circ} \mathrm{C}$. Plates were read (excitation $530 \mathrm{~nm}$, emission $590 \mathrm{nM}$ ) using an Enspire multilabel reader (2300 EnSpire ${ }^{\mathrm{TM}}$ Multilabel Reader, PerkinElmer, Turku, Finland) at various time points, and the linear increase of fluorescence was used as a marker for cell viability. ${ }^{43}$

\section{In vitro cytotoxicity assessment in human foreskin fibroblasts (HFF)}

The cytotoxicity of $\mathbf{A B Z}$ and its derivatives in HFF host cells was assessed as previously described. ${ }^{44}$ Briefly, HFF were grown to confluence in 96 well-plates. The medium was removed, and monolayers received $200 \mu \mathrm{l}$ fresh medium containing either $0.1,1$ or $10 \mu \mathrm{M}$ of each compound, or the medium was supplemented with the corresponding concentrations of DMSO. Following cultivation at $37^{\circ} \mathrm{C} /$ $5 \% \mathrm{CO}_{2}$ for $72 \mathrm{~h}$, the medium was aspirated, and cells were washed once with PBS. Subsequently, $200 \mu \mathrm{l}$ PBS containing resazurin $(10 \mathrm{mg} / \mathrm{ml})$ were added per well. Plates were read (excitation 530 $\mathrm{nm}$, emission $590 \mathrm{nM}$ ) using an Enspire multilabel reader (2300 EnSpire ${ }^{\mathrm{TM}}$ Multilabel Reader, PerkinElmer, Turku, Finland) at different timepoints between 0 and $5 \mathrm{~h}$. The cytotoxicity was calculated and is represented as percentage of the DMSO control. 


\section{In vitro activity against the protozoan Toxoplasma gondii}

For the assessment of drug efficacy against Toxoplasma tachyzoites, transgenic T. gondii $\beta$-gal tachyzoites ( $\mathrm{RH}$ background, constitutively expressing $\beta$-galactosidase) ${ }^{45}$ were cultured in human foreskin fibroblasts (HFF) host cells as previously described. ${ }^{46}$ Assays were carried out in 96 well plates. $5 \times 10^{3} \mathrm{HFF} /$ well were grown to confluency in $200 \mu$ phenol-red free culture medium at 37 ${ }^{\circ} \mathrm{C}$ and $5 \% \mathrm{CO}_{2}$. Monolayers were infected with freshly isolated T. gondii $\beta$-gal tachyzoites $\left(1 \times 10^{3} /\right.$ well) and drugs were added concomitantly with infection. Assessment of drug efficacy was done by exposing parasite cultures to $0.1,1,10 \mu \mathrm{M}$ (quadruplicates) of each compound (40 mM stock solutions), and respective concentrations of DMSO were added to control wells. After $72 \mathrm{~h}$ of culture in the presence of the drugs at $37^{\circ} \mathrm{C} / 5 \% \mathrm{CO}_{2}$, the medium was removed by aspiration, wells were washed once with $200 \mu \mathrm{l}$ PBS and cells were permeabilized with $90 \mu \mathrm{l}$ PBS containing $0.05 \%$ Triton $\mathrm{X}-100$. After addition of $10 \mu \mathrm{L}$ of $5 \mathrm{mM}$ chlorophenol red- $\beta$-D-galactopyranoside (CPRG; Roche Diagnostics, Rotkreuz, Switzerland) dissolved in PBS, the absorption shift was measured at $570 \mathrm{~nm}$ wavelength at various time points on a EnSpire ${ }^{\circledR}$ multimode plate reader (Perkin Elmer). The activity, measured as the release of chlorophenol red over time, was calculated as percentage from DMSO control, which represented $100 \%$ of $T$. gondii growth.

\section{ASSOCIATED CONTENT}

Supporting Information contains detailed synthetic procedures and characterizations of the compounds and copies of the NMR spectra, details concerning the X-ray analyses and copies of the HPLC chromatograms for the plasma stability assays.

\section{AUTHOR INFORMATION}

\section{Corresponding Authors}

*e-mail: kevin.cariou@cnrs.fr

* e-mail: jennifer.keiser@swisstph.ch

* e-mail: gilles.gasser@chimieparistech.psl.eu

\section{ORCID:}

Yan Lin: 0000-0001-7808-5444

Yih Ching Ong: 0000-0003-0411-1114

Sarah Keller: 0000-0003-2667-9157 
Johannes Karges: 0000-0001-5258-0260

Rafika Bouchene: 0000-0003-0688-8365

Eric Manoury: 0000-0001-7991-8890

Aya C. Taki: 0000-0003-3489-4367

Andrew Hemphill: 0000-0002-0622-2128

Robin B. Gasser: 0000-0002-4423-1690

Kevin Cariou: 0000-0002-5854-9632

Jennifer Keiser: 0000-0003-0290-3521

Gilles Gasser: 0000-0002-4244-5097

\section{Author Contribution}

All authors were involved with the design and interpretation of experiments and with the writing of the manuscript. K.C., J.K. and G.G. have conceived and supervised the study. Synthesis and characterization of the compounds were performed by Y. L. and R.B. with assistance from Y.C.O., S.K. \& J.K. Biological experiments were carried out by J.M., N.A., A.H., A.C.T., R.B.G., J.K.. X-ray crystallography was carried out by O.B. Animal testing was carried out by J.K. All authors have given approval to the final version of the manuscript. The authors thank Sabrina Lebrequier and DavidAlexandre Buisson for excellent analytical support (Université Paris-Saclay, Service de Chimie Bioorganique et Marquage, CEA, 91191, Gif-sur-Yvette, France).

\section{Funding Information}

This work was financially supported by the Swiss National Science Foundation (Grant Sinergia CRSII5_173718, to G.G.), an ERC Consolidator Grant PhotoMedMet to G.G. (GA 681679) and has received support under the program Investissements d'Avenir launched by the French Government and implemented by the ANR with the reference ANR-10-IDEX-0001-02 PSL (G.G.). Y.L. thanks to the China Scholarship Council for financial support. Funding from the Australian Research Council, Yourgene Health and The University of Melbourne is gratefully acknowledged. 


\section{REFERENCES}

1. WHO. (2012). Why are some tropical diseases called 'neglected'? https://www.who.int/features/qa/58/en/

2. WHO. (2017). Neglected tropical diseases. http://www.who.int/neglected_diseases/diseases/en/

3. Hess, J., Panic, G., Patra, M., Mastrobuoni, L., Spingler, B., Roy, S., Keiser, J. and Gasser, G. (2017). Ferrocenyl, Ruthenocenyl, and Benzyl Oxamniquine Derivatives with Cross-Species Activity against Schistosoma mansoni and Schistosoma haematobium. ACS Infect. Dis. 3 (9), 645-652.

4. Campbell, S. J., Nery, S. V., McCarthy, J. S., Gray, D. J., Soares Magalhães, R. J. and Clements, A. C. A. (2016). A Critical Appraisal of Control Strategies for Soil-Transmitted Helminths. Trends Parasitol. $32(2), 97-107$.

5. Lo, N. C., Addiss, D. G., Hotez, P. J., King, C. H., Stothard, J. R., Evans, D. S., Colley, D. G., Lin, W., Coulibaly, J. T., Bustinduy, A. L., Raso, G., Bendavid, E., Bogoch, I. I., Fenwick, A., Savioli, L., Molyneux, D., Utzinger, J. and Andrews, J. R. (2017). A call to strengthen the global strategy against schistosomiasis and soil-transmitted helminthiasis: the time is now. Lancet Infect. Dis. 17 (2), e64-e69.

6. $\quad$ Bethony, J., Brooker, S., Albonico, M., Geiger, S. M., Loukas, A., Diemert, D. and Hotez, P. J. (2006). Soil-transmitted helminth infections: ascariasis, trichuriasis, and hookworm. The Lancet 367 (9521), $1521-1532$.

7. Chami, G. F. and Bundy, D. A. P. (2019). More medicines alone cannot ensure the treatment of neglected tropical diseases. Lancet Infect. Dis. 19 (9), e330-e336.

8. WHO. (2019). Soil-transmitted helminth infections. https://www.who.int/news-room/factsheets/detail/soil-transmitted-helminth-infections

9. $\quad$ Ehteda, A., Galettis, P., Chu, S. W. L., Pillai, K. and Morris, D. L. (2012). Complexation of Albendazole with Hydroxypropyl- $\beta$ - Cyclodextrin Significantly Improves its Pharmacokinetic Profile, Cell Cytotoxicity and Antitumor Efficacy in Nude Mice. ANTICANCER Res. 8.

10. Horton, J. (2000). Albendazole: a review of anthelmintic efficacy and safety in humans. Parasitology 121 (S1), S113-S132.

11. Lubega, G. W. and Prichard, R. K. (1991). Interaction of benzimidazole anthelmintics with Haemonchus contortus tubulin: Binding affinity and anthelmintic efficacy. Exp. Parasitol. 73 (2), 203-213.

12. Lanusse, C. E. and Prichard, R. K. (1993). Clinical Pharmacokinetics and Metabolism of Benzimidazole Anthelmintics in Ruminants. Drug Metab. Rev. 25 (3), 235-279.

13. Waghorn, T., Leathwick, D., Rhodes, A., Jackson, R., Pomroy, W., West, D. and Moffat, J. (2006). Prevalence of anthelmintic resistance on 62 beef cattle farms in the North Island of New Zealand. N. Z. Vet. J. 54 (6), 278-282.

14. WHO. One Health. https://www.who.int/news-room/q-a-detail/one-health

15. Rivas, F., Medeiros, A., Rodríguez Arce, E., Comini, M., Ribeiro, C. M., Pavan, F. R. and Gambino, D. (2018). New heterobimetallic ferrocenyl derivatives: Evaluation of their potential as prospective agents against trypanosomatid parasites and Mycobacterium tuberculosis. J. Inorg. Biochem. 187 73-84. 
16. Hillard, E. A., Vessières, A. and Jaouen, G. (Springer Berlin Heidelberg, 2010). Ferrocene Functionalized Endocrine Modulators as Anticancer Agents. in Medicinal Organometallic Chemistry (eds. Jaouen, G. \& Metzler-Nolte, N.) 32 81-117.

17. Golbaghi, G., Haghdoost, M. M., Yancu, D., López de los Santos, Y., Doucet, N., Patten, S. A., Sanderson, J. T. and Castonguay, A. (2019). Organoruthenium(II) Complexes Bearing an Aromatase Inhibitor: Synthesis, Characterization, in Vitro Biological Activity and in Vivo Toxicity in Zebrafish Embryos. Organometallics 38 (3), 702-711.

18. Barry, N. P. E. and Sadler, P. J. (2013). Exploration of the medical periodic table: towards new targets. Chem. Commun. 49 (45), 5106-5131.

19. Gasser, G. and Metzler-Nolte, N. (2012). The potential of organometallic complexes in medicinal chemistry. Curr. Opin. Chem. Biol. 16 (1), 84-91.

20. Gasser, G., Ott, I. and Metzler-Nolte, N. (2011). Organometallic Anticancer Compounds. J. Med. Chem. 54 (1), 3-25.

21. Brown, R. W. and Hyland, C. J. T. (2015). Medicinal organometallic chemistry - an emerging strategy for the treatment of neglected tropical diseases. MedChemComm 6 (7), 1230-1243.

22. Hess, J., Patra, M., Jabbar, A., Pierroz, V., Konatschnig, S., Spingler, B., Ferrari, S., Gasser, R. B. and Gasser, G. (2016). Assessment of the nematocidal activity of metallocenyl analogues of monepantel. Dalton Trans. 45 (44), 17662-17671.

23. Hess, J., Patra, M., Pierroz, V., Spingler, B., Jabbar, A., Ferrari, S., Gasser, R. B. and Gasser, G. (2016). Synthesis, Characterization, and Biological Activity of Ferrocenyl Analogues of the Anthelmintic Drug Monepantel. Organometallics 35 (19), 3369-3377.

24. Hess, J., Patra, M., Rangasamy, L., Konatschnig, S., Blacque, O., Jabbar, A., Mac, P., Jorgensen, E. M., Gasser, R. B. and Gasser, G. (2016). Organometallic Derivatization of the Nematocidal Drug Monepantel Leads to Promising Antiparasitic Drug Candidates. Chem. - Eur. J. 22 (46), 16602-16612.

25. Ong, Y. C., Roy, S., Andrews, P. C. and Gasser, G. (2019). Metal Compounds against Neglected Tropical Diseases. Chem. Rev. 119 (2), 730-796.

26. Patra, M., Ingram, K., Pierroz, V., Ferrari, S., Spingler, B., Keiser, J. and Gasser, G. (2012). Ferrocenyl Derivatives of the Anthelmintic Praziquantel: Design, Synthesis, and Biological Evaluation. J. Med. Chem. 55 (20), 8790-8798.

27. Hess, J., Keiser, J. and Gasser, G. (2015). Toward organometallic antischistosomal drug candidates. Future Med. Chem. 7 (6), 821-830.

28. Biot, C., Glorian, G., Maciejewski, L. A., Brocard, J. S., Domarle, O., Blampain, G., Millet, P., Georges, A. J., Abessolo, H., Dive, D. and Lebibi, J. (1997). Synthesis and Antimalarial Activity in Vitro and in Vivo of a New Ferrocene-Chloroquine Analogue. J. Med. Chem. 40 (23), 3715-3718.

29. Biot, C., Nosten, F., Fraisse, L., Ter-Minassian, D., Khalife, J. and Dive, D. (2011). The antimalarial ferroquine: from bench to clinic. Parasite J. Société Fr. Parasitol. 18 (3), 207-214.

30. Dombrowski, K. E., Baldwin, W. and Sheats, J. E. (1986). Metallocenes in biochemistry, microbiology \& medicine. J. Organomet. Chem. 302 (3), 281-306. 
31. Hillard, E. A., Vessières, A. and Jaouen, G. (Springer, 2010). Ferrocene Functionalized Endocrine Modulators as Anticancer Agents. in Medicinal Organometallic Chemistry (eds. Jaouen, G. \& Metzler-Nolte, N.) $81-117$.

32. Schatzschneider, U. and Metzler-Nolte, N. (2006). New Principles in Medicinal Organometallic Chemistry. Angew. Chem. Int. Ed. 45 (10), 1504-1507.

33. Gasser, G., Fischmann, A. J., Forsyth, C. M. and Spiccia, L. (2007). Products of hydrolysis of (ferrocenylmethyl)trimethylammonium iodide: Synthesis of hydroxymethylferrocene and bis(ferrocenylmethyl) ether. J. Organomet. Chem. 692 (17), 3835-3840.

34. Noshita, M., Shimizu, Y., Morimoto, H. and Ohshima, T. (2016). Diethylenetriamine-Mediated Direct Cleavage of Unactivated Carbamates and Ureas. Org Lett 4.

35. Keller, S., Ong, Y. C., Lin, Y., Cariou, K. and Gasser, G. (2020). A tutorial for the assessment of the stability of organometallic complexes in biological media. J. Organomet. Chem. 906121059.

36. Patra, M., Ingram, K., Pierroz, V., Ferrari, S., Spingler, B., Gasser, R. B., Keiser, J. and Gasser, G. (2013). [ $\left(\eta^{6}\right.$-Praziquantel $\left.) \mathrm{Cr}(\mathrm{CO})_{3}\right]$ Derivatives with Remarkable In Vitro Anti-schistosomal Activity. Chem. - Eur. J. 19 (7), 2232-2235.

37. Dayan, A. D. (2003). Albendazole, mebendazole and praziquantel. Review of non-clinical toxicity and pharmacokinetics. Acta Trop. 86 (2-3), 141-159.

38. Buchter, V., Priotti, J., Leonardi, D., Lamas, M. C. and Keiser, J. (2020). Preparation, Physicochemical Characterization and In Vitro and In Vivo Activity Against Heligmosomoides polygyrus of Novel Oral Formulations of Albendazole and Mebendazole. J. Pharm. Sci. 109 (5), 1819-1826.

39. Hall, C. A., Kelly, J. D., Campbell, N. J., Whitlock, H. V. and Martin, I. C. A. (1978). The dose response of several benzimidazole anthelmintics against resistant strains of Haemonchus contortus and Trichostrongylus colubriformis selected with thiabendazole. Res. Vet. Sci. 25 (3), 364-367.

40. Lombardo, F. C., Pasche, V., Panic, G., Endriss, Y. and Keiser, J. (2019). Life cycle maintenance and drug-sensitivity assays for early drug discovery in Schistosoma mansoni. Nat. Protoc. 14 (2), 461-481.

41. Preston, S., Jabbar, A., Nowell, C., Joachim, A., Ruttkowski, B., Baell, J., Cardno, T., Korhonen, P. K., Piedrafita, D., Ansell, B. R. E., Jex, A. R., Hofmann, A. and Gasser, R. B. (2015). Low cost wholeorganism screening of compounds for anthelmintic activity. Int. J. Parasitol. 45 (5), 333-343.

42. Muller, J., Ruhle, G., Muller, N., Rossignol, J.-F. and Hemphill, A. (2006). In Vitro Effects of Thiazolides on Giardia lamblia WB Clone C6 Cultured Axenically and in Coculture with Caco2 Cells. Antimicrob. Agents Chemother. 50 (1), 162-170.

43. Bénéré, E., da Luz, R. A. I., Vermeersch, M., Cos, P. and Maes, L. (2007). A new quantitative in vitro microculture method for Giardia duodenalis trophozoites. J. Microbiol. Methods 71 (2), 101-106.

44. Schorer, M., Debache, K., Barna, F., Monney, T., Müller, J., Boykin, D. W., Stephens, C. E. and Hemphill, A. (2012). Di-cationic arylimidamides act against Neospora caninum tachyzoites by interference in membrane structure and nucleolar integrity and are active against challenge infection in mice. Int. J.

Parasitol. Drugs Drug Resist. 2 109-120. 
45. Mcfadden, D. C., Seeber, F. and Boothroyd, J. C. (1997). Use of Toxoplasma gondii Expressing NLGalactosidase for Colorimetric Assessment of Drug Activity In Vitro. ANTIMICROB AGENTS CHEMOTHER 415.

46. Barna, F., Debache, K., Vock, C. A., Küster, T. and Hemphill, A. (2013). In Vitro Effects of Novel Ruthenium Complexes in Neospora caninum and Toxoplasma gondii Tachyzoites. Antimicrob. Agents Chemother. 57 (11), 5747-5754.

\section{Graphical Abstract}

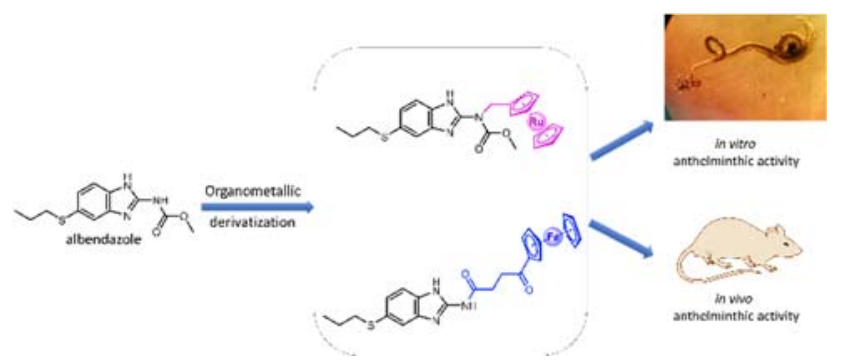

